\title{
Leukoerythroblastic Reaction
}

National Cancer Institute

\section{Source}

National Cancer Institute. Leukoerythroblastic Reaction. NCI Thesaurus. Code C36218.

A laboratory test result indicating the presence of nucleated red blood cells and immature leukocytes in the peripheral blood. It is observed in disorders causing extramedullary hematopoiesis such as myelofibrosis and metastatic cancer to the bone marrow. 